\title{
THE FIRST REPORT ON CRYPTOCOCCUS PROFILES OF ISOLATES FROM PATIENTS ATTENDING DR GEORGE MUKHARI ACADEMIC HOSPITAL, SOUTH AFRICA
}

Authors Affiliations: Elliot Zwelibanzi Jiyane'; BSc, PGCE, BSc Hons (Med), MSc (Micro). Sefako Makgatho Health Science University, Oral Health Center, School of Dentistry, Department of Oral Microbiology, Pretoria, South Africa; email address: elliot.jiyane@smu.ac.za

Mis Leah Nemarude ${ }^{2}$; BSc, BSc Hons, MSc Viro (Med). Sefako Makgatho Health Science University, Microbiological Pathology, School of Medicine, Pretoria, South Africa; email address: leah.nemarude@smu.ac.za

Prof Maphoshane Nchabeleng; ${ }^{3}$ MBChB, MMed. Sefako Makgatho Health Science, University Microbiological Pathology, School of Medicine, Pretoria, South Africa; email address: maphoshane.nchabeleng@smu.ac.za

Corresponding author: Jiyane ${ }^{1}$ (zwellyelliot@gmail.com)

Mailing address: Medunsa Campus, PO Box CP30, Sefako Makgatho Health Science University, 0204

E-mail address: elliot.jiyane@smu.ac.za

\begin{abstract}
Introduction: Cryptococcosis is a fungal opportunistic infection that is vastly diagnosed among immune-compromised patients. Reduced susceptibility on commonly used antifungals is of concern. In the communities served by Dr. George Mukhari Tertiary (DGMTLaboratory) Laboratory is not available.

Methodology: E-test method was used to determine if isolates with reduced susceptibility to antifungals fluconazole, voriconazole and amphotericin-B had emerged. A multiplex Polymerase Chain Reaction (PCR) method was used to further identify serotypes that are circulating at Dr. George Mukhari Tertiary (DGMT-Hospital) Hospital.
\end{abstract}

Results: E-test strips were interpreted as resistance, intermediate or susceptible in relation to each serotype identified. Of the 50 incident isolates tested, 100\% were inhibited by both voriconazole and amphotericin-B. Fluconazole was resistance to $50 \%$ of incident isolates.

Conclusion: $C$. neoformans serotype A is the predominant serotype in the area served by DGMT-Laboratory, accounting for $96 \%$ of the isolates. It is important for public health to continuously monitor resistance emergence.

Keywords: cryptococcosis, serotypes 
43 Cryptococcosis is amongst the leading and 44 life-threatening opportunistic infection ${ }^{[1]}$.

45 The disease is caused by Cryptococcus

46 neoformans (C. neoformans) and

47 Cryptococcus gattii (C. gattii), which are

48 vastly diagnosed among immune-

49 compromised patients ${ }^{[2]}$. Mainly $C$.

50 neoformans, with three recognized

51 serotypes which are acknowledged as

52 serotype A, serotype D and the hybrid-

$53 \mathrm{AD}^{[3]}$. Previously, these serotypes were

54 identified and differentiated by the

55 phenotypic approach ${ }^{[4]}$. Lately, are

56 identified by PCR assays ${ }^{[5]}$. More methods

57 of molecular assays are used to classify $C$.

58 neoformans serotypes ${ }^{[6]}$. The classification

59 is based on antigenic metamorphoses in

60 the polysaccharide capsule associated with

61 virulence factors ${ }^{[3,7]}$. Prevalently found

62 circulating globally is serotype A, whereas

63 serotype D and AD hybrid circulating in

64 truncated numbers ${ }^{[1-3]}$. Serotype A account

65 for more than $90 \%$ cases of cryptococcosis

66 in South Africa owing to the extraordinary

67 occurrence of HIV/AIDS ${ }^{[2,8,9,10]}$.

69 To treat cryptococcosis, the most widely

70 used antifungal agents are amphotericin-B,

71 flucytosine, voriconazole and

72 fluconazole ${ }^{[9,11]}$. Amphotericin-B is used

73 as the first line treatment but limited by

74 toxicity that requires laboratory

75 monitoring, voriconazole is limited to

76 private sectors in Africa ${ }^{[9-12]}$. The

77 amalgamations of antifungals are

78 recommended for induction but

79 flucytosine is not available in resource-

80 poor countries ${ }^{[12]}$. Unfortunately, these are

81 countries with a high incidence of

82 cryptococcosis ${ }^{[10-12]}$. All these antifungals

83 are also limited by emerging resistance

84 mechanisms such as the antigenic

85 polysaccharide capsule tolerance, the

86 mating gene types, the acid tolerant

87 abilities, and spores switching ${ }^{[12]}$.

88 Globally, $20-58 \%$ of resistance cases are

89 reported on cryptococcosis by means of

90 diverse studies, focusing on fluconazole ${ }^{[8-}$
99 The widespread use of fluconazole may 100 lead to the emergence of reduced 101 susceptibility ${ }^{[19,20]}$. Thus the development 102 of resistance to fluconazole is devastating 103 to the treatment of cryptococcosis, and it is 104 necessary to know if there is cross105 resistance with voriconazole which could 106 be an alternative agent. It is important for 107 institutions to monitor for changes in 108 susceptibility profiles of isolates 109 circulating in their areas in order to update 110 the treatment regimens. Our aim in this 111 study was to identify circulating serotypes 112 and determination of the susceptibility 113 profiles of Cryptococcus isolates to 114 fluconazole, voriconazole and 115 amphotericin-B antifungals form clinical 116 specimens sent to the DGMT-Hospital 117 NHLS.

Sample size: Epi Info version 3.5.3 128 (Centre for Disease Control and 129 Prevention) was used to calculate the 130 sample size. The required sample size in 131 this study was 50. This was calculated at 132 an estimated frequency of $50 \%$, power of $13380 \%$ and the confidence interval of $95 \%$.

134 Demographics: Demographic data 135 including age, sex and clinical diagnosis of 136 patients from whom the isolates were 137 isolated was obtained from the Laboratory 138 Information Systems (LIS) in the 139 laboratory. 
140 Collection and storage of isolates:

141 Clinical isolates were conveniently

142 collected from the laboratory after

143 processing for patient management was

144 completed. The isolates were collected

145 from February-July 2014, on a day to day

146 basis until the sample size was reached.

147 These isolates were already identified by

148 the NHLS as Cryptococcus and stored in a

$149-4^{\circ} \mathrm{C}$ fridge.

150

151

152

153

154 Govender et al. 2011 ${ }^{[9]}$.

170 Susceptibility Testing: After sub-culturing 171 on SDA (Figure 1), susceptibility testing 172 was achieved according to Clinical and

173 Laboratory Standards Institution (CLSI) 174 outlines of $2007^{[24]}$ and as described by 175 Govender et al. 2011, 2013 ${ }^{[9,25]}$. to verify the presence of capsule ${ }^{[22]}$. The
177 DNA Extraction and Sample Preparation 178 for Multiplex PCR: Genomic DNA was 179 extracted from the clinical isolates using 180 the commercial kit (ZR fungal/bacterial 181 DNA MiniPrep kit) in accordance with the 182 manufacturer's instructions (Zymo 183 research group). The kit has been 184 optimized for removal of PCR inhibitors 185 and maximal recovery of pure DNA 186 without RNA contamination. The 187 extraction of DNA from the isolates was 188 done using the protocol, "Biological 189 liquids and cell suspensions"

190

Primers selection: The primers used were 193 Industries (Pty) Ltd, Muckleneuk, and 193 Industries (Pty) Ltd, Muckleneuk, and 194 Pretoria. The serotypes specific primers 195 were designed to target the Mating - $\alpha$ 196 gene and Mating - a gene of both serotypes $197 \mathrm{~A}$ and $\mathrm{D}^{[27]}$. Primers targeting for genes 198 confirming $C$. neoformans serotypes are 199 listed in table 3.

200

201

202

203

204 205

Confirmation and identification of 208 Cryptococcus: Gram staining was done to 209 confirm the morphology of yeast cell 210 according to Chayakulkeeree (2007) 211 description $^{[21]}$. India ink (negative stain) 212 was done as described by Ogundeji (2013) 213

Amplification of genes: This was done on the extracted DNA using specific primers (Table 3). Two master-mixtures (MM) were prepared. Reagents were obtained from Bioline Meridian Life Science Company (UK), each PCR assay was setup with nuclease-free water as the negative control (Bioline, UK), and positive controls were not included due to financial constraints. MyTaq ${ }^{\mathrm{TM}}$ HS DNAPolymerase (Bioline, UK) was used in the PCR reactions.

For each sample, a $50 \mu 1$ reaction MM was prepared following the manufacturer's instructions (Bioline, UK).

Briefly: $10 \mu \mathrm{L}$ x MyTaq $^{\mathrm{TM}} \mathrm{HS}$ buffer, 1 $\mu \mathrm{L}$ of each of 2 primers, $5 \mu \mathrm{L}$ of the template, $0.5 \mu \mathrm{L}$ MyTaq ${ }^{\mathrm{TM}} \mathrm{HS}$ DNAPolymerase (Bioline, UK) (5 U/ $\mu \mathrm{L})$, and $32,5 \mu \mathrm{L}$ nuclease-free water. Two sets of MM were used, in MM1 contained alpha$\mathrm{A} a$-D primer set and the MM2 contained a-Aalpha-D. The $0.2 \mathrm{~mL}$ PCR tubes each containing $50 \mu \mathrm{L}$ placed into a reaction 
227 was allowed to take place in a GeneAmp 228 PCR System 9700 (MTHE 01326 PE 229 Applied Biosystems) thermocycler for 3 230 hours; succeeding PCR temperatures as 231 described by Saiki (1999) ${ }^{[28]}$.

271 Study population: There were 50 272 Cryptococci isolates collected from 273 different clinical specimens sent to the 274 DGMT-Laboratory during the study 275 period, June to October 2014 (5 months).

276 277 278 279

Detection of amplified products: 282 Electrophoresis was performed on all 283 samples using 2,0\% agarose gel (Crystal 284 TBE, Bioline, UK) for 40 minutes at 100285 $\mathrm{V}$, with ethidium bromide and UV 286 transilluminator (Gel Doc ${ }^{\mathrm{TM}} \mathrm{EZ}$ System). The $1 \mathrm{~kb}$ molecular weight marker (HyperLadder IV, Bioline, UK) was used in together with the amplified products. The photographic copy was taken using a Gel Doc EZ imager and the results were recorded as representative of serotype-A $\alpha$, $\mathrm{D} \alpha$ or A-a, D-a genes. For expected bands see table 3 .

Capturing of data: Microsoft Excel (Microsoft Office, 2010) was used to analyze data and the captured data was double-checked to ensure reliability; Epi Info version 3.5.3 (Centers for Disease Control \& Prevention). Descriptive statistical analysis was performed based on ANOVA excel, 2010. Measures of central tendency and dispersion were calculated for continuous variables (e.g. age); frequencies and proportions of categorical data (e.g. serotypes) were calculated.

Reliability, Validity, and Objectivity: All tests were performed according to recognized, accredited standard operating procedures as well as to the instructions of the manufactures in the case where commercially available kits were used. Molecular size markers were used during agarose gel electrophoresis.

\section{RESULTS}

Eleven $(22 \%)$ isolates were from blood specimens and 39 (78\%) from Cerebral Spinal Fluid (CSF).

Table 1: Demographics of the patients: Only 41 of the 50 patients from where the clinical specimens were sent had complete information from the laboratory information system.

\begin{tabular}{|l|l|l|}
\hline Females & Males & Unknown \\
\hline $30(60 \%)$ & $11(22 \%)$ & $9(18 \%)$ \\
\hline
\end{tabular}

The ages of the 41 patients analyzed ranged from 15 to 86 with the majority being between 35 and 45 .

Biochemical test for species: Urease slope was done to all 50 isolates. After a period of 24 hours incubation at $30^{\circ} \mathrm{C}$, the color change was observed. The change of colorless broth to pink broth medium was confirming the presence of $C$. neoformans species (figure 2 ).

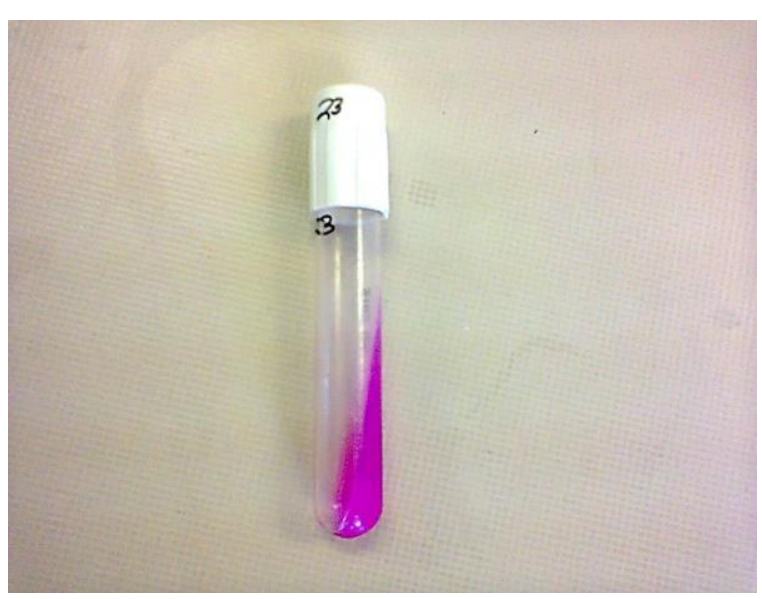

Figure 2: Urease slope of one of the isolates showing a colour change after 24 hours incubation.

Susceptibility testing: After the incubation period of the three antifungals E-test strips (bioMe'rieux S.A., Marcy l'Etoile, France) which were fluconazole, voriconazole, and amphotericin-B, results were then read following the CLSI ${ }^{\text {[24] }}$. The Minimum inhibitory concentration (MIC) values were read at the point of intersection between the zones of growth and the edge 
311 of the strip. The amphotericin-B was read

312 at the point of complete inhibition $(100 \%)$

313 as shown in figure $\mathbf{3}$, both fluconazole and

314 voriconazole MICs were read at a point of

315 significant inhibition of growth, about

$31680 \%$ reduction of growth as shown in

317 figure 4 and 5a-b. MIC values were

318 documented on a data collection sheet. The

319 MIC values for fluconazole and

320 voriconazole were interpreted in

321 accordance with CLSI updated M27

322 breakpoints (2013) guideline and for

323 amphotericin B, according to NCCLS M27

324 guideline $^{[24]}$. These were interpreted as

325 susceptible, intermediate and resistant.

\section{inhibition of growth}

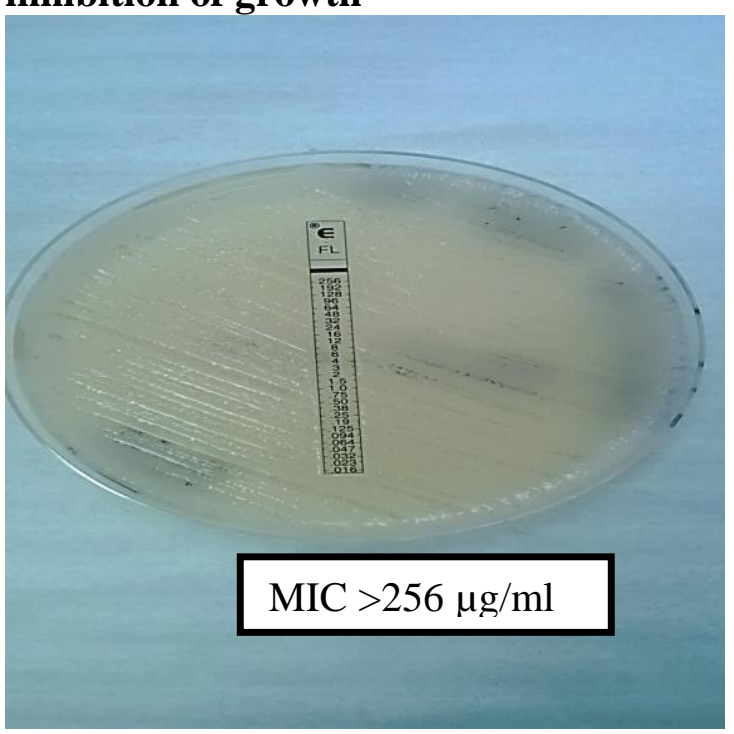

341 The MICs were determined in all isolates.

342 Voriconazole and amphotericin-B were

343 susceptible to all isolates as presented in

344 table 4 above.

345

346 Table 2: Molecular confirmation of

347 serotypes: PCR for serotyping of $C$.

348 neoformans was performed on all 50

349 isolates.

\begin{tabular}{|l|c|c|c|c|c|}
\hline \multicolumn{5}{|c|}{ Master-mix 1 (MM1) } & \multicolumn{3}{|l|}{ Master-mix 2 (MM2) } \\
\hline \multicolumn{5}{|c|}{ Serotypes } \\
\hline A- $\alpha$ & D-a & AD- $\alpha \mathrm{a}$ & A-a & D- $\alpha$ & AD-a $\alpha$ \\
\hline $48(96 \%)$ & - & - & - & $2(4 \%)$ & - \\
\hline
\end{tabular}


The agarose gel picture below, show representatives of PCR results on an agarose electrophoresis

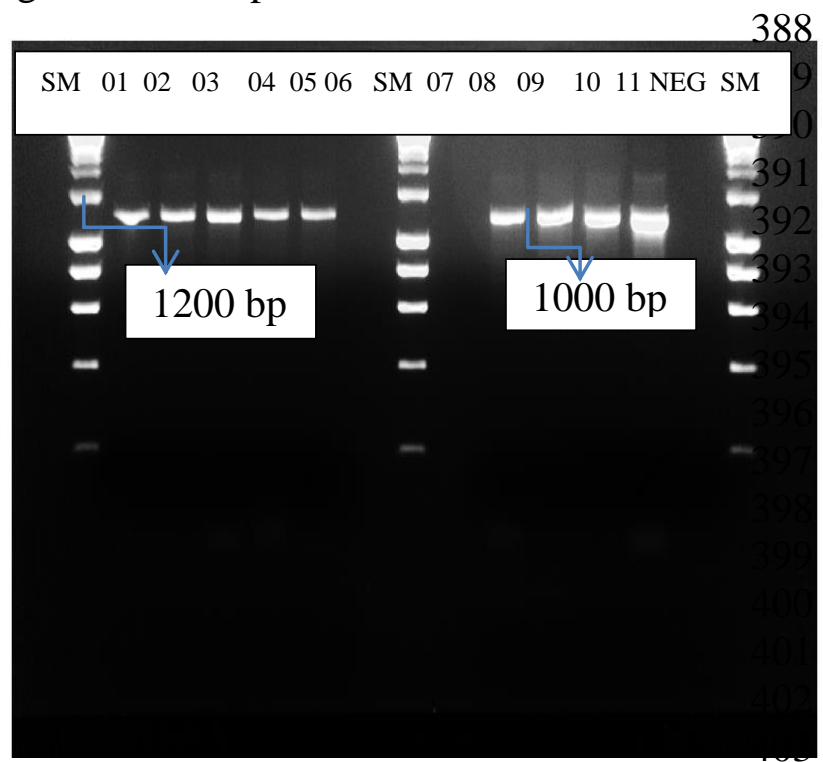

Figure: Representative Agarose gel electrophoresis. Where: Lane 1-11: Clinical isolates; Neg: Negative control; SM: 1000 bp (1 kd) (size markers); Lane number: $2-5$; $8-11$ represent serotype $A \alpha$ mating genes; Lane number: 6-7 negative results.

\section{DISCUSSION}

Resistance to antifungal agents used against cryptococcosis is globally reported $^{[9,16,29-31]}$. In Africa, cryptococcosis epidemiology data is scarce but accumulated evidence in South Africa, makes it apparent that resistance development to commonly used antifungal agents is of concern ${ }^{[8-10,25]}$. Therefore, monitoring the susceptibility of these commonly used antifungal agents in different geographical areas is essential.

Data on circulating serotypes responsible for cryptococcosis in communities served by DGMT-Laboratory is not available. This study serves to profile the susceptibility and to identify the circulating serotypes of Cryptococcus at DGMT-hospital, in South Africa.

Based on our study, the susceptibility of the amphotericin-B, fluconazole, and
385 voriconazole was profiled; resistance to fluconazole was of foremost concern (table 4).

It was not surprising to see that half of our isolates were completely resistant to fluconazole. Our results were in keeping with multiple studies of diverse geographic areas, such that Arsenijevic et al (2014) in Serbia revealed $60 \%$ resistance of clinical isolates $^{[32]}$, and that of $63 \%$ by Favalessa et al (2014) in West Brazil patients ${ }^{[33]}$. Furthermore, a South African report of Govender et al (2011) and (2013) showed $58 \%$ resistance to fluconazole $e^{[9,25]}$.

Fluconazole resistance is based on the $C$. neoformans mechanisms of action ${ }^{[8,16,-18]}$. The other factors that contribute to the recurrence of cryptococcosis among South African patients are limited access to treatment and inadequate treatment ${ }^{[8-10,25]}$. 407

408 Furthermore, isolates of our study were 409 highly susceptible to voriconazole and 410 amphotericin-B. Our findings were not 411 different but comparable to the studies of 412 Arsenijevic et al (2014) ${ }^{[32]}$, Govender et al 413 (2011) and (2013), they all reported 100\% 414 susceptibility on voriconazole and 415 amphotericin- $\mathrm{B}^{[9,25]}$. There was no cross416 resistance between amphotericin-B, 417 voriconazole, and fluconazole on in-vitro 418 testing. It will, however, be important to 419 assess this based on clinical outcome in 420 patients.

421

422 Unfortunately, Amphotericin-B had no 423 breaking-points according to CLSI 424 updated M27 break-points document of 425 2013, we, therefore, interpreted our results 426 in accordance with NCCLS M27-A 427 guideline document (NCCLS M27-A 428 guideline, 2000) ${ }^{[24]}$. Fortunately Govender 429 et al (2011) also, however, indicated the 430 challenges of performing susceptibility 431 testing for amphotericin-B because of the 432 absence of CLSI break-points ${ }^{[9]}$. 
434 Molecular-based, our study confirmed that

435 C. neoformans serotype A is predominant

436 in our setting. Accumulated evidence

437 showed that serotype A has been reported

438 as more virulent and prevalent than the

439 other serotypes $^{[32-36]}$. Likewise, Lugarini et

440 al (2008) in Brazil, reported a prevalence

441 of $53 \%$ serotype A $\alpha$-mating gene types

442 circulating across the country ${ }^{[34]}$. A similar

443 study by Favalessa et al (2014) in Midwest

444 Brazil also reported serotype A making

$44563 \%$ of the isolates from HIV/AIDS

446 patients $^{[33]}$. Khayhan et al (2013) also

447 confirmed serotype $A$ as the most

448 prevalent serotype in Asia Phayoa ${ }^{[35]}$. In

449 our study, we didn't manage to find the

450 HIV status of our patients. Our study was

451 in keeping with a systemic review study of

452 Litvintseva et al (2011) which was

453 conducted in African countries, reported

454 serotype A specifically the $\alpha$-mating gene

455 types to account for $79 \%$ of the isolates ${ }^{[36]}$,

456 and according to our study in South

457 Africa, serotype $\mathrm{A}$ is the commonest

458 circulating serotype across our setting,

459 counting for $96 \% \alpha$-mating gene types.

460 Furthermore, our study showed that only a

461 few isolates were confirmed to be serotype

$462 \mathrm{D} \alpha$-mating genes type. Those few isolates

463 were from patients over the age of 65

464 Duke University in Durham previously

465 reported that serotype D is very rare and

466 less information is documented about the

467 distribution of this serotype ${ }^{[37]}$, whereas

468 Feretzaki et al (2014) in India reported that

469 serotype D requires very high inoculum to

470 disseminate and cause infections like

471 meningitis ${ }^{[38]}$. There is no information or

472 data documented about the distribution of

473 serotype D $\alpha$-mating gene-types in South

474 Africa and in our setting. Our two patients

475 could have been more immune-

476 compromised than the others because of

477 their age. Furthermore, no study has been

478 conducted according to our knowledge on

479 serotypes and mating-genes in South
480 Africa, Pretoria, DGMT-Hospital. Our 481 results highlight the importance of 482 properly treating cryptococcosis.

483

484

485

486

487

488

489

490

491

492

493

494

495

496

497

498

499

500

501

502

503

504

505

506

507

508

509

510

511

512

513

514 Conceived and designed the experiments:

515 EZ Jiyane. Performed the experiments: EZ

516 Jiyane, Analysed the data: EZ Jiyane,

517 Contributed reagents/materials/analysis

518 tools: VLIR, EZ Jiyane; Contributed to the

519 writing of the manuscript: EZ Jiyane;

520 critically reviewed the manuscript: EZ

521 Jiyane, L Nemarude, Prof M Nchabeleng.

522

523

524

\section{Funding sources}

All funds were received from VLIR.

c. neoformans serotype $A$ is a DGMT Laboratory, accounting for $96 \%$ of the isolates. Fifty percent of the isolates of those tested were susceptible to suggesting a lack of cross-resistance on inThe study had several limitations such as population number and financial fluconazole resistance suggested, the study recommends the routine performance of resistance with voriconazole and We thank NHLS for assisting with isolates collections, and VLIR for reagents.

\section{Conflict of Interest}

The authors declare no conflicts of interest with respect to authorship and/or publication of this article.
525

526 


\section{REFERENCES}

1. Limper AH, Adenis A, Le T, Harrison 579 TS. Fungal infections in HIV/AIDS. 580 The Lancet Infect Dis. 2017; 581 17(11):e334-43.

582 https://doi.org/10.1016\%2Fs1473- 583 3099\%2817\%2930303-1

584 585

2. Kwon-Chung KJ, Fraser JA, Doering 586 TL et al. Cryptococcus neoformans 587 and Cryptococcus gattii, the etiologic 588 agents of cryptococcosis. Cold Spring 589 Harb Perspect Med. 2014; 4(7): 590 a019760. 591 https://doi.org/10.1101\%2Fcshperspect 592 .a019760

593

594

3. Cogliati M, Esposto MC, Clarke DL, 595 Wickes BL, Viviani MA. Origin of 596 Cryptococcus neoformans var. 597 neoformans diploid strains. J Clin 598 Microbiol. 2001; 39(11): 3889-3894. 599 https://doi.org/10.1128\%2Fjcm.39.11.3 600 889-3894.2001

601

602

4. Khan ZU, Al-Anezi AA, Chandy R, 603 $\mathrm{Xu}$ J. Disseminated cryptococcosis in 604 an AIDS patient caused by a 605 canavanine-resistant strain of 606 Cryptococcus neoformans var. grubii. J 607 Med Microbiol. 2003; 52(3): 271-275. 608 https://doi.org/10.1099\%2Fjmm.0.050 609 97-0

610

611

5. Firacative C, Trilles L, Meyer W. 612 MALDI-TOF MS enables the rapid 613 identification of the major molecular 614 types within the Cryptococcus 615 neoformans/C. gattii species complex. 616 PloS one. 2012; 7(5): e37566. 617 https://doi.org/10.1371\%2Fjournal.pon 618 e.0037566

619

6. Sidrim JJC, Costa AK, Cordeiro RA et 621 al. Molecular methods for the 622 diagnosis and characterization of 623 Cryptococcus: a review. Can J 624 Microbiol. 2010; 56(6): 445-458. 625 https://doi.org/10.1139\%2Fw10-030 626
7. Cherniak R, Jones RG, Reiss E. Structure determination of Cryptococcus neoformans serotype Avariant glucuronoxylomannan by $13 \mathrm{C}$ n.m.r. spectroscopy. Carbohydr Res. 1988; $\quad 172(1)$ : $113-138$. https://doi.org/10.1016\%2Fs00086215\%2800\%2990846-2

8. Van Wyk M, Govender NP, Mitchell TG, Litvintseva AP. Multilocus sequence typing of serially collected isolates of Cryptococcus from HIVinfected patients in South Africa. J Clin Microbiol. 2014; 52(6): 1921-31. https://doi.org/10.1128\%2Fjcm.0317713

9. Govender NP, Meintjes G, Bicanic T et al. Guideline for the prevention, diagnosis, and management of cryptococcal meningitis among HIVinfected persons: 2013 update. S Afr J HIV Med. 2013; 14(2): 76-86. https://doi.org/10.4102\%2Fsajhivmed. v14i2.82

10. Jarvis JN, Harrison TS, Lawn SD, Meintjes G, Wood R, Cleary S. Costeffectiveness of cryptococcal antigen screening as a strategy to prevent HIVassociated cryptococcal meningitis in South Africa. PloS one. 2013; 8(7): e69288.

https://doi.org/10.1371\%2Fjournal.pon e. 0069288

11. Loyse A, Wilson D, Meintjes G et al. Comparison of the early fungicidal activity of high-dose fluconazole, voriconazole, and flucytosine as second-line drugs given in combination with amphotericin B for the treatment of HIV-associated cryptococcal meningitis. Clin Infect Dis. 2011; 54(1):121-128. https://doi.org/10.1093\%2Fcid\%2Fcir7 45 
12. Srinivasan A, Lopez-Ribot JL, 677 Ramasubramanian AK. Overcoming 678 antifungal resistance. Drug Discovery 679 Today: Technologies. 2014; 11: 65-71. 680 https://doi.org/10.1016\%2Fj.ddtec.201 681 4.02.005

682

683

13. Park BJ, Wannemuehler KA, Marston 684 BJ, Govender N, Pappas PG, Chiller 685 TM. Estimation of the current global 686 burden of cryptococcal meningitis 687 among persons living with HIV/AIDS. 688 AIDS. 2009; 23(4): 525-530. 689 https://doi.org/10.1097\%2Fqad.0b013e 690 $328322 \mathrm{ffac}$

691

692

14. Pianalto K, Alspaugh J. New horizons 693 in antifungal therapy. J Fungi. 2016; 694 2(4): 26. 695 https://doi.org/10.3390\%2Fjof2040026 696 5. Saag MS, Graybill RJ, Larsen RA et 698 al. Practice guidelines for the 699 management of Cryptococcal disease. 700 Infectious Diseases Society of 701 America. Clin Infect Dis. 2000; 30(4): 702 710-718. https://doi.org/10.1086\%2F313757 704

16. Kanafani ZA, Perfect JR. 706 Antimicrobial resistance: resistance to 707 antifungal agents: mechanisms and 708 clinical impact. Clin Infect Dis. 2008; 709 46: 120-128. 710 https://doi.org/10.1086\%2F524071 711

17. Pfaller MA. Antifungal drug 713 resistance: mechanisms, epidemiology, 714 and consequences for treatment. Am J 715 Med. 2012; 125(1): S3-S13. 716 https://doi.org/10.1016\%2Fj.amjmed.2 717 011.11 .001

18. Almeida F, Wolf JM, Casadevall A. 720 Virulence-associated enzymes of 721 Cryptococcus neoformans. Eukaryot 722 Cell. 2015; 14(12): 1173-1185. 723 https://doi.org/10.1128\%2Fec.00103- 724 15
19. Matuschek E, Åhman J, Kahlmeter G, Yagupsky P. Antimicrobial susceptibility testing of Kingella kingae with broth microdilution and disk diffusion using EUCAST recommended media. Clinical Microbiology and Infection. Elsevier BV; 2018; 24(4): 396-401. Available from:

http://dx.doi.org/10.1016/j.cmi.2017.0 7.019

20. Loyse A, Thangaraj H, Easterbrook $P$ et al. Cryptococcal meningitis: improving access to essential antifungal medicines in resource-poor countries. Lancet Infect Dis. 2013; 13(7):629-637. https://doi.org/10.1016\%2Fs14733099\%2813\%2970078-1

21. Chayakulkeeree M, Perfect JR. Diagnosis of Cryptococcosis. Infect Dis Ther. 2007; 47: 239. https://doi.org/10.3109\%2F978142001 7182.010

22. Chan MY, Tay ST. Enzymatic characterization of clinical isolates of Cryptococcus neoformans, Cryptococcus gattii, and other environmental Cryptococcus spp. Mycoses. Wiley; 2010; 53(1):26-31. Available from: http://dx.doi.org/10.1111/j.14390507.2008.01654.x

23. Gazzoni FA, Elsemann RB, Conde A, Galafassi D, Gazzoni AF. Updating: cryptococcosis diagnostic aspects. J AIDS Clin Res. 2014; 5(12): 391. https://doi.org/10.4172\%2F21556113.1000391

24. Jorgensen JH, Hindler JF, Reller LB, Weinstein MP. New consensus guidelines from the Clinical and Laboratory Standards Institute for antimicrobial susceptibility testing of infrequently isolated or fastidious 
bacteria. Clin Infect Dis. 2007; 44(2): 776 280-286. 777 https://doi.org/10.1086\%2F510431 778 779

25. Govender NP, Patel J, van Wyk M, 780 Chiller TM, Lockhart SR. for the 781 Group for Enteric, respiratory a 782 meningeal disease surveillance in 783 South Africa (GERMS-SA). Trends in 784 antifungal drug susceptibility of 785 Cryptococcus neoformans isolates 786 obtained through population-based 787 surveillance in South Africa in 2002- 788 2003 and 2007-2008. Antimicrob 789 Agents Chemother. 2011; 55(6): 2606- 790 2611. https://doi.org/10.1128\%2Faac.00048- 792 11

26. Meyne nee Haase N, Fuge G, Trieu 795 HK, Zeng A-P, Jacob AF. 796 Miniaturized Transmission-Line 797 Sensor for Broadband Dielectric 798 Characterization of Biological Liquids 799 and Cell Suspensions. IEEE 800 Transactions on Microwave Theory 801 and Techniques. IEEE; 2015; 63(10): 802 3026-3033. Available from: 803 http://dx.doi.org/10.1109/tmtt.2015.24 804 72009

27. Yang Z, Pascon RC, Alspaugh A, Cox 807 GM, McCusker JH. Molecular and 808 genetic analysis of the Cryptococcus 809 neoformans MET3 gene and a met3 810 mutants. Microbiology. 2002; 811 148(8):2617-2625. https://doi.org/10.1099\%2F00221287- 813 148-8-2617

28. Saiki RK. Amplification of genomic 816 DNA. PCR protocols: A guide to 817 methods and applications. 1990; 2:13- 818 20. https://doi.org/10.1016\%2Fb978-0- 819 12-372180-8.50006-8

29. Peman J, Canton E, Espinel-Ingroff A. 822 Antifungal drug resistance 823 mechanisms. Expert Rev Anti Infect 824
Ther. 2009; 7(4):453-460. https://doi.org/10.1586\%2Feri.09.18

30. Pfaller MA, Messer SA, Boyken L et al. Global trends in the antifungal susceptibility of Cryptococcus neoformans (1990 to 2004). J Clin Microbiol. 2005; 43(5):2163-7. https://doi.org/10.1128\%2Fjcm.43.5.21 63-2167.2005

31. Pfaller MA, Castanheira M, Messer SA, Moet GJ, Jones RN. Variation in Candida spp. distribution and antifungal resistance rates among bloodstream infection isolate by patient age: report from the SENTRY Antimicrobial Surveillance Program (2008-2009). Diagn Microbiol Infect Dis. 2010; 68(3):278-283. https://doi.org/10.1016\%2Fj.diagmicro bio.2010.06.015

32. Arsic Arsenijevic V, Pekmezovic MG, Meis JF, Hagen F. Molecular epidemiology and antifungal susceptibility of Serbian Cryptococcus neoformans isolates. Mycoses. 2014; 57(6):380-387. https://doi.org/10.1111\%2Fmyc.12171

33. Favalessa OC, de Paula DA, Dutra V et al. Molecular typing and in vitro antifungal susceptibility of Cryptococcus spp from patients in Midwest Brazil. J Infect Dev Ctries. 2014; $\quad$ 8(8): 1037-1043. https://doi.org/10.3855\%2Fjidc.4446

34. Lugarini C, Goebel CS, Condas LA et al. Cryptococcus neoformans isolated from Passerine and Psittacine bird excreta in the state of Paraná, Brazil. Mycopathologia. 2008; 166(2): 61-69. https://doi.org/10.1007\%2Fs11046008-9122-3

35. Khayhan K, Hagen F, Pan W, et al. Geographically structured populations of Cryptococcus neoformans Variety 
864

865

866

867 grubii in Asia correlate with HIV 844 status and show a clonal population 845 structure. PLoS One. 2013; 8(9): 846 e72222. 847 https://doi.org/10.1371\%2Fjournal.pon 848 e. 0072222

36. Litvintseva AP, Carbone I, Rossouw J, 851 Thakur R, Govender NP, Mitchell T.G. 852 Evidence that the human pathogenic 853 fungus Cryptococcus neoformans var. 854 grubii may have evolved in Africa. 855 PLoS ONE. 2011; 6(5): e19688. 856 https://doi.org/10.1371\%2Fjournal.pon 857 e.0019688

858 859
Genetic diversity and genomic plasticity of Cryptococcus neoformans AD hybrid strains. G3: Genes, Genomes, Genetics. 2012; 2(1):83-97. https://doi.org/10.1534\%2Fg3.111.001 255

38. Feretzaki M, Hardison SE, Wormley Jr FL, Heitman J. Cryptococcus neoformans hyperfilamentous strain is hypervirulent in a murine model of cryptococcal meningoencephalitis. PloS one. 2014; 9(8):e104432. https://doi.org/10.1534\%2Fg3.111.001 255

37. Li W, Averette AF, Desnos-Ollivier M, Ni M, Dromer F, Heitman J.

Table 3: Combination and sequences of the primers used for the determination of serotype and mating type of $C$. neoformans by PCR multiplex alpha-Aa-D and aAalpha-D (N= 50)

\begin{tabular}{|c|c|c|c|}
\hline $\begin{array}{l}\text { Gene } \\
\text { alleles }\end{array}$ & Primers & Sequence 5'3' & $\begin{array}{l}\text { PCR product } \\
\text { - (bp) }\end{array}$ \\
\hline $\begin{array}{c}M A T \alpha \\
\text { serotype-A } \\
(\mathrm{MM} 1)\end{array}$ & $\begin{array}{l}\text { JOHE } 7264 \\
\text { JOHE } 7265\end{array}$ & $\begin{array}{l}\text { AGCTGATGCTGTGGATTGAATAC } \\
\text { GTTCAATTAATCTCACTACCTGTAG }\end{array}$ & 1200 \\
\hline $\begin{array}{c}M A T a \\
\text { serotype D } \\
(\mathrm{MMI})\end{array}$ & $\begin{array}{l}\text { JOHE } 7273 \\
\text { JOHE } 7275\end{array}$ & $\begin{array}{l}\text { GTTCATCAGATACAGAGGAGTGG } \\
\text { CTCCACTGTCAAACCTACGGC }\end{array}$ & 870 \\
\hline $\begin{array}{c}\text { MATa } \\
\text { serotype A } \\
\text { (MM2) }\end{array}$ & $\begin{array}{l}\text { JOHE } 7270 \\
\text { JOHE } 7272\end{array}$ & $\begin{array}{c}\text { ATCAGAGACAGAGGAGGAGCAAGAC } \\
\text { TCCACTGGCAACCCTGCGAG }\end{array}$ & 870 \\
\hline 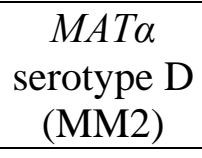 & $\begin{array}{l}\text { JOHE } 7267 \\
\text { JOHE } 7268\end{array}$ & $\begin{array}{l}\text { ATAGGCTGGTGCTGTGAATTAAG } \\
\text { GTTCAAGTAATCTCACTACATGCG }\end{array}$ & 1200 \\
\hline
\end{tabular}

Table 4: MIC's of the isolates against common antifungals $(\mathrm{N}=50)$

\begin{tabular}{|l|c|c|c|}
\hline Antifungal drugs & Interpretation & MIC scales & Isolates numbers \\
\hline \multirow{3}{*}{$* *$ Fluconazole } & Susceptible & $\leq 2 \mu \mathrm{g} / \mathrm{mL}$ & $13(26 \%)$ \\
\cline { 2 - 4 } & Intermediate & $4 \mu \mathrm{g} / \mathrm{mL}$ & $12(24 \%)$ \\
\cline { 2 - 4 } & Resistant & $\geq 8 \mu \mathrm{g} / \mathrm{mL}$ & $25(50 \%)$ \\
\hline
\end{tabular}


*interpretation according to NCCLS M27-A document 2000

\begin{tabular}{|c|c|c|c|}
\hline \multirow{3}{*}{$* *$ Voriconazole } & Susceptible & $\leq 0.12 \mu \mathrm{g} / \mathrm{mL}$ & $50(100 \%)$ \\
\cline { 2 - 4 } & Intermediate & $\begin{array}{c}0.25 \mu \mathrm{g} / \mathrm{mL}- \\
0.5 \mu \mathrm{g} / \mathrm{mL}\end{array}$ & 0 \\
\cline { 2 - 4 } & Resistant & $\geq 1 \mu \mathrm{g} / \mathrm{mL}$ & 0 \\
\hline \multirow{2}{*}{$*$ Amphotericin-B } & Susceptible & $\leq 0.5 \mu \mathrm{g} / \mathrm{mL}$ & $50(100 \%)$ \\
\cline { 2 - 4 } & Intermediate & - & 0 \\
\cline { 2 - 4 } & Resistant & $\geq 2 \mu \mathrm{g} / \mathrm{mL}$ & 0 \\
\hline
\end{tabular}

870 **interpretation according to CLSI M27-A document 2013

871

872

873

874

875

876

877

878

879

880

881

882

883

884

885

886

887

888

889

890 